\title{
Canine and Human Dirofilariosis in the Rostov Region (Southern Russia)
}

\author{
Vladimir Kartashev, ${ }^{1}$ Irina Batashova, ${ }^{1}$ Sergey Kartashov, ${ }^{2}$ Alexey Ermakov, ${ }^{2}$ \\ Anna Mironova, ${ }^{2}$ Yulia Kuleshova, ${ }^{2}$ Boris Ilyasov, ${ }^{3}$ Irina Kolodiy, ${ }^{2}$ \\ Alexander Klyuchnikov, ${ }^{2}$ Elena Ryabikina, ${ }^{1}$ Marina Babicheva, ${ }^{1}$ Yulia Levchenko, ${ }^{1}$ \\ Raisa Pavlova, ${ }^{1}$ Nicola Pantchev, ${ }^{4}$ Rodrigo Morchón, ${ }^{5}$ and Fernando Simón ${ }^{5}$ \\ ${ }^{1}$ Rostov State Medical University, Per. Nakhichevansky 29, 344022 Rostov-na-Donu, Russia \\ ${ }^{2}$ North Caucasus Veterinary Research Institute, Rostov Highway 0, 346421 Novocherkassk, Rostov Region, Russia \\ ${ }^{3}$ Rostov Regional Diagnostic Center, Ul. Pushkinskaya 127, 344000 Rostov-na-Donu, Russia \\ ${ }^{4}$ Vet Med Labor GmbH Division of IDEXX Laboratories, Mörikestrasse 28/3 71636 Ludwigsburg, Germany \\ ${ }^{5}$ Laboratory of Parasitology, Faculty of Pharmacy, University of Salamanca, Avenida Licenciado Méndez Nieto s/n, \\ 37007 Salamanca, Spain
}

Correspondence should be addressed to Fernando Simón, fersimon@usal.es

Received 17 October 2010; Revised 24 November 2010; Accepted 14 December 2010

Academic Editor: Dimosthenis E. Miliaras

Copyright ( 2011 Vladimir Kartashev et al. This is an open access article distributed under the Creative Commons Attribution License, which permits unrestricted use, distribution, and reproduction in any medium, provided the original work is properly cited.

\begin{abstract}
Epidemiological data on canine and human dirofilariosis in the Rostov Region (Southern Russia) are presented. Prevalence of Dirofilaria spp. infections in 795 autochthonous dogs, assessed by the Knott test, was $20.25 \%$. The highest prevalence was found in Novocherkassk $(38.3 \%)$ and Rostov-on-Don (18.5\%), while prevalences were lower in other points of the region. Prevalence of $D$. repens was $44.7 \%$, prevalence of $D$. immitis was $30.3 \%$, and coinfections were observed in $25.0 \%$ of the dog population. A case finding study carried out during 9 years (2000-2009) revealed 131 cases of human dirofilariosis in the Rostov Region, 129 of subcutaneous dirofilariosis and 2 of pulmonary dirofilariosis. Seroprevalence among 317 healthy blood donors from the Rostov Region was $10.4 \%$, while seroprevalence in policemen living in Rostov city and working in training dogs was $19 \%$. These data show high infection rates of Dirofilaria spp. in both human and dog populations of Rostov, probably because of the existence of favorable conditions for the transmission in this region.
\end{abstract}

\section{Introduction}

Different Dirofilaria species are responsible for canine and feline dirofilariosis worldwide. These species can also be transmitted to humans causing zoonotic infections when they are bitten by culicid mosquitoes containing infective L3 larvae. D. immitis, with a cosmopolitan distribution, and $D$. repens, only reported in the Old World, are the main causative agents of animal and human dirofilariosis in Europe [1]. In spite of dirofilariosis being endemic in the Mediterranean countries, it has been demonstrated a significant increase of cases in dogs from central and Northern European countries, attributed, among other factors, to the climatic change and the increase of pet travels [2].
In fact, prediction models based on the use of Geographic Information System (GIS) and Remote Sensing (RS) indicate that suitable conditions for the transmission of dirofilariosis can be done, during a short period of time each year, in Northern European areas [3]. Consistent with the changing conditions and the spreading of canine dirofilariosis in Europe, human cases are being detected with increasing frequency in nonendemic countries, or in countries where dirofilariosis was not previously known $[1,4]$.

In Russia (or the former Soviet Union), the first cases of canine dirofilariosis caused by $D$. repens were found by Petropavlovsky (1904) in the Kharkov region (Ukraine), near the border of the Rostov Region, in the Bukhara region (Metelkin, 1927), and in the Rostov Region (Gurvich, 1929) 
[5]. D. immitis was reported for the first time by Gogel (1910) in dogs from the territory of Azerbaijan Republic. Later this species was also identified by Skryabin and Yakimov (1916) in Turkmenistan Republic, in the Far East Ussuri region by Petrov (1931), and in Abkhazia by Blazhin (1937) [6]. In addition to these scattered reports, there are some epidemiological studies that reveal a prevalence of $D$. repens in 30\% of dogs from the Rostov Region [6] and 11\% in dog from other regions of the Russia but living in Rostov [7].

Less information exists about human dirofilariosis. The first cases of human dirofilariosis in the Rostov Region, caused by $D$. repens, were published by Savchenko [8]. Two cases were autochthonous and other two cases were imported from other territories (Krasnodar city and Grozny, Chechnya). Artamonova [5] reported other two cases, and by 1997 the number of human cases had increased to 23 [6]. Currently, dirofilariosis is considered an emerging disease in the Rostov Region, in accordance with the increasing frequency of the reports and the data revealed by a preliminary report [9].

The aim of this study was to determine the prevalence of canine dirofilariosis from different places of the Rostov Region and its dependence on the type of housing and management of the dogs. Moreover, we present epidemiological data on human dirofilariosis that suggest the close relationship between the human activity and the risk level of infection by Dirofilaria species.

\section{Materials and Methods}

2.1. Dogs. We examined the blood samples of 795 autochthonous dog that sought veterinary attention in different cities of the Rostov Region (South Western Russia) between 2002-2009: Rostov-on-Don (314), Novocherkassk (245), Shakhty (112) and Taganrog (124). The presence of Dirofilaria infections was assessed by the presence of blood microfilariae using the Knott test [10]. The species causing the infections (D. immitis or D. repens) were studied in 76 microfilaremic dogs obtained in veterinary clinics of Rostov-na-Donu, using two specific tests: the IDEXX test that detects antigens from adult females of $D$. immitis and PCR with specific primers for $D$. repens described by Favia et al. [11]. Thus, with these three tests, we were able to detect Dirofilaria spp. infections, D. immitis or D. repens infections and mixed infections. In addition autopsies were performed in 21 dogs that had died from heartworm disease. Moreover, the influence of the type of housing was analyzed by the IDEXX test in 75 serum samples of dogs living outdoors and 67 serum samples of dogs living indoors.

2.2. Humans. Studies in humans were made by two different ways to determine both the real incidence of clinical Dirofilaria nodules and the risk of infection of the human population living in the Rostov Region: (1) Clinical cases finding study during the development of the research (20022009). People were received and operated on different surgery departments (general, oral, ophthalmology, paediatric, gynaecologic surgery, etc.) of different hospitals of

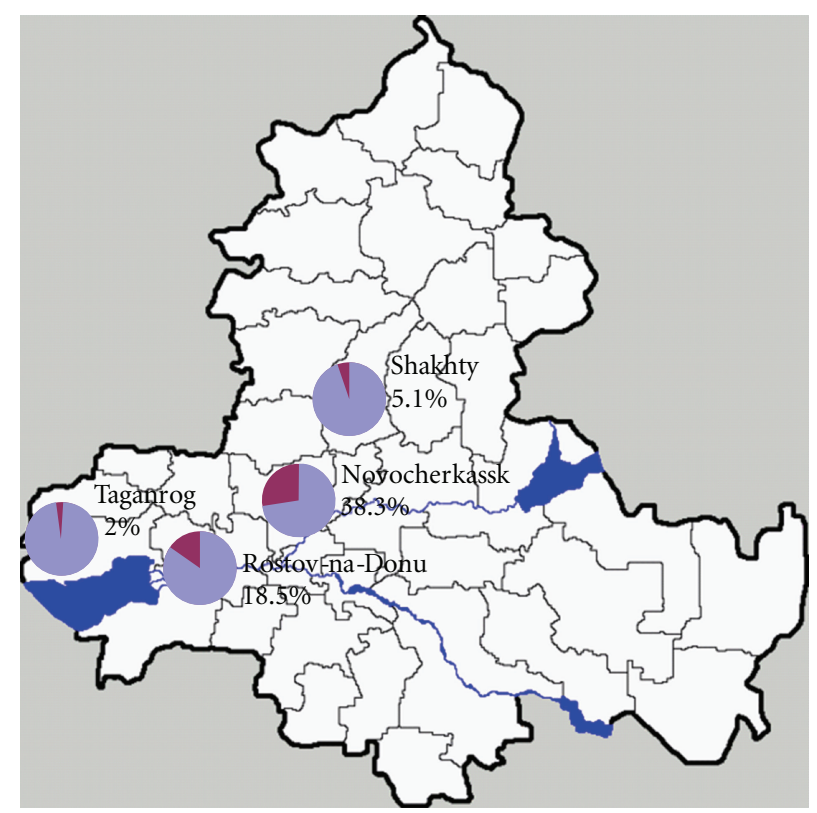

FIGURE 1: Rostov Region map. Occurrence of canine dirofilariosis at different points of the Region.

Rostov-on-Don. The excised worms were then identified in the laboratory using microscopic examination and morphological criteria. Identification was carried out at the time of the surgery or immediately after in all cases. In most cases the diagnosis of dirofilariosis was postoperative. In conjunctival location alive and active moving Dirofilaria worms were detected by ophthalmoscopic examination. These cases were also analyzed after surgery by histology. (2) seroepidemiological studies in 317 healthy blood donors aged 20 to 60 years. These serum samples were analyzed by ELISA tests to detect both anti- $D$. immitis and $D$. repens IgG antibodies using the technique described by Simón et al. [12] in which a serum sample was considered positive when it surpasses an Optical Density (OD) of 0.8 in each analysis (mean OD of 20 healthy donors living in a nonendemic area plus 3 times their standard deviation). A second seroepidemiological study was made in 110 policemen dedicated to the management and training dogs. Of these, 42 were resident in the Rostov Region and the others lived in different places of Russia.

2.3. Statistical Analyses. The results were analyzed using the SAS statistical package (13.0). The prevalence values were compared by Chi-square test. A significant difference was defined as a $P$ value of $<.5$, for a confidence level of $95 \%$.

\section{Results}

3.1. Dirofilariosis in Dogs. Microfilariae were detected in 161 dogs indicating a prevalence of $20.25 \%$ of Dirofilaria spp. infections in the canine population of the Rostov Region. The highest prevalences were found in Novocherkassk (94/245, $38.3 \%)$ and Rostov-on-Don $(58 / 314,18.5 \%)$, followed by Shakhty $(6 / 112,5.1 \%)$ and Taganrog $(3 / 124,2.0 \%)$, existing significant differences among them $(P<.05)$ (Figure 1$)$. 


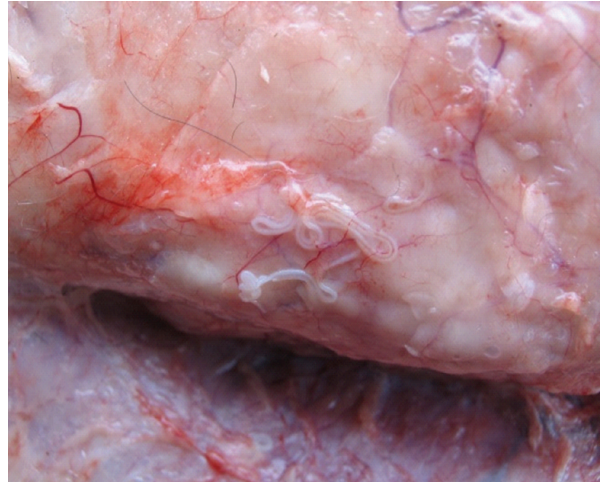

(a)

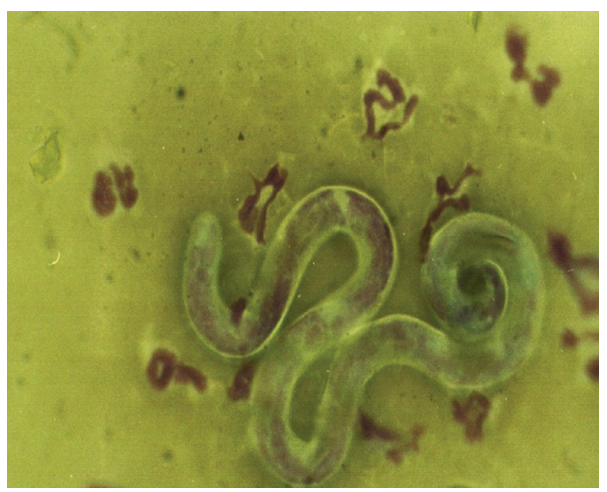

(c)

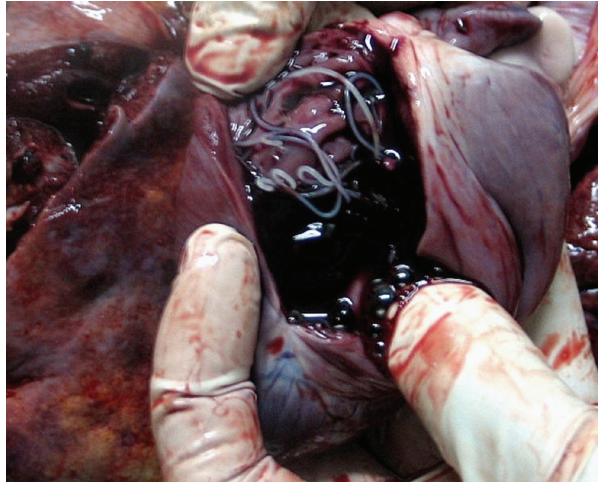

(b)

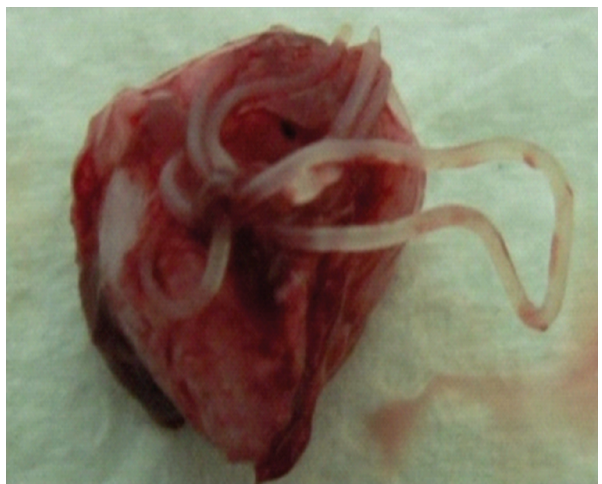

(d)

Figure 2: Representative images of the parasites observed in dogs and humans during the study. Canine subcutaneous dirofilariosis (a). Canine cardiopulmonary dirofilariosis (b). D. repens microfilariae from the blood of an infected dog (c). Human subcutaneous dirofilariosis. Excised nodule containing a $D$. repens adult worm $(\mathrm{d})$.

Considering the housing of dogs, Dirofilaria spp. microfilariae were detected in 27/75 (36\%) of the dogs living outdoors and in 6/67 (9\%) of the dogs living indoors. Thus the probability to be infected is 4 times higher in dogs living outdoor than those living indoor. There were significant differences between the 2 groups $(P<.05)$. The causative agent analyzed in 76 dogs from Rostov city was $D$. repens in 34 dogs (44.7\%) (Figures 2(a), 2(b), and 2(c)), D. immitis in 23 dogs (30.3\%), and mixed infections (D. repens/D. immitis) were observed in 19 dogs (25\%). So the rate of dogs infected by $D$. immitis alone or by its combination with $D$. repens accounted for $55.3 \%$. Postmortem examination of 21 dogs that died as a result of a massive invasion of $D$. immitis showed that in 11 out of 21 animals (52\%) coinfections of D. immitis and D. repens exist.

3.2. Dirofilariosis in Humans. The case finding study carried out during 9 years (2002-2009) revealed 131 cases of human dirofilariosis in the Rostov Region. The number of reported cases had increased significantly after 2003. The highest incidence was observed in people aged 30-39 years. Considering the sex, there are significative differences between women and men $(P<.05)$. In fact, women were much more affected (93 out of 131, 71\%) than men (38 out of 131,29\%). Subcutaneous location of the parasite was observed in 129 patients, which caused by $D$. repens (Figure 2(d)). The other two patients presented pulmonary nodules most likely caused by $D$. immitis. The most frequent localization of subcutaneous nodular lesions was the head $(58.1 \%)$, mainly the eye area $(38.2 \%)$. Nodules appeared in the extremities in $24 \%$ of the cases (lower extremities $15.5 \%$; upper extremities $8.5 \%$ ). The third location was the trunk (12.4\%). Rare but special localization was genitals (6.2\%). This location was observed only in adolescent boys from 8 to 14 years of age.

To assess the risk of infection by Dirofilaria in the resident of the Rostov Region a seroepidemiological study in 317 healthy blood donors was carried out (Figure 3). Thirtythree samples presented specific anti-Dirofilaria spp. IgG antibodies. From these, 9 were positive only to D. immitis, 5 were positive only to $D$. repens and 19 were positive to both species. Thus, we can consider that 33 out of 317 (10.4\%) healthy blood donors presented significant levels of antiDirofilaria spp. antibodies. Among 110 policemen working in training dogs, 10 presented positive result to both $D$. immitis and $D$. repens antibody tests $(9 \%)$. Forty two policemen live in Rostov city. Of these, 8 were positive to both tests, indicating a seroprevalence of $19 \%$ in the policemen living in this city. 


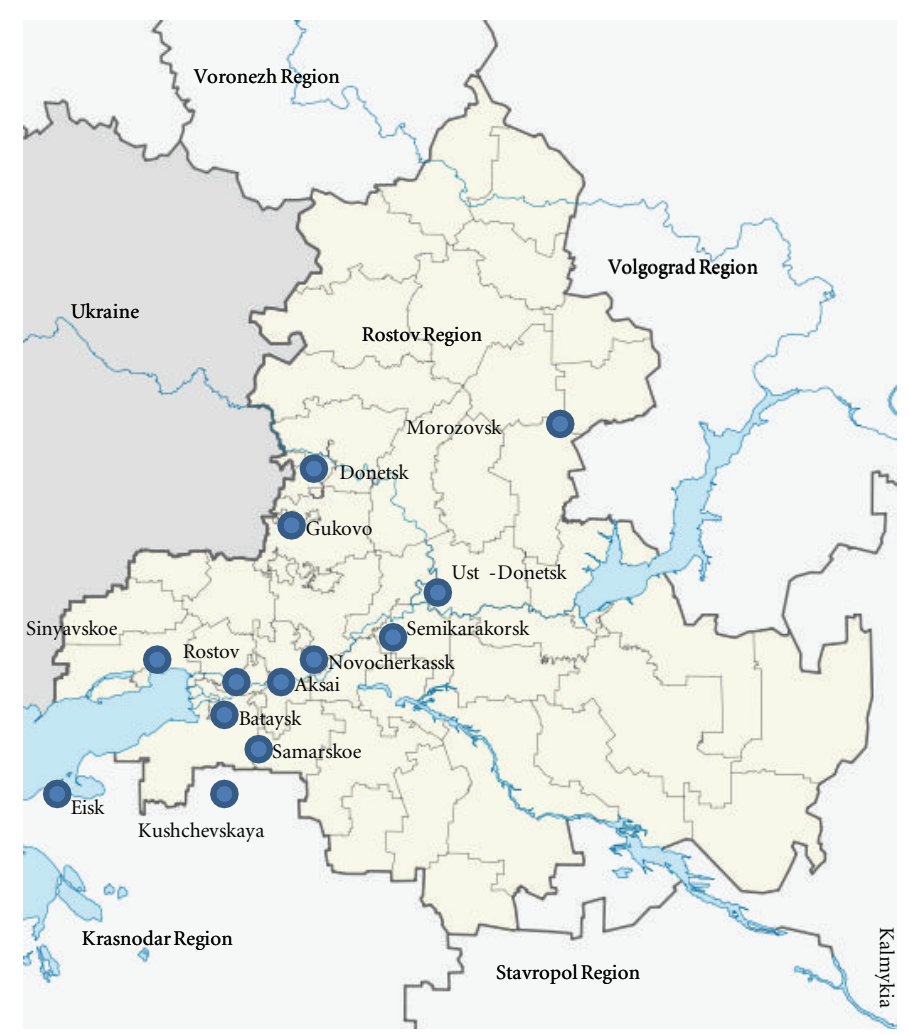

FIGURE 3: Rostov Region map. It is indicated the living places of the human healthy blood donors that have antibodies to Dirofilaria spp. somatic antigens.

\section{Discussion}

D. immitis and D. repens are the two main species causing zoonotic filariosis in Europe. The distribution and incidence of cardiopulmonary and subcutaneous dirofilariosis have experienced accelerated changes as a consequence, among other factors, of pet travels, the climatic change and a higher veterinary and medical alert $[1,2]$. In the last few years a rise of cases in both animal reservoirs and human populations of the central and Eastern European countries it has been detected [1]. Nevertheless, in some countries data are scarce, thus it is not possible an analysis of the trend of the epidemiological situation. The objective of this work is to show updated information of the situation of the canine and human dirofilariosis in the Rostov Region (Southern Russia).

Our data suggest a high incidence of the disease in some areas of the Region, in contrast with the significantly lower incidence in others. In the capital of the region, Rostovon-Don, and in Novocherkassk, prevalences of $18.5 \%$ and $38.3 \%$, respectively were observed, while in small towns prevalences are lower. Most likely, these differences are due to the intensity of transmission related to the involved mosquitoes species and their density, the abundance of dogs and their management by the owners. This is confirmed by the analysis of the prevalence in dogs living indoors or outdoors in Rostov-on-Don. This analysis showed that the risk of infection by Dirofilaria spp. is four times higher for dogs living outdoors, at least in this part of the Region. It is likely related to the exposure to mosquito bites, which are more intense in animals living outdoors. Another interesting feature is the high prevalence of coinfections (D. repens and D. immitis). D. immitis was less common as monoinfection than $D$. repens but in total $55.3 \%$ of dogs were infected or coinfected with $D$. immitis. This is supported by the postmortem examination of 21 dogs with severe heartworm infection. In 11 of these animals $D$. repens was present as the second infective agent. To our knowledge that kind of coinfections is rarely reported in the literature [13].

The high prevalence of canine dirofilariosis can explain both the great number of clinical cases and the seroprevalence observed in humans. This is, likely, the greatest series of clinical cases described until now by one research team, in the same country, over a period of time. Moreover, other human cases have been identified by an active search in the pathology archives from different hospitals of the Rostov Region (data not shown), indicating that human dirofilariosis is common in the Rostov population, but it has not been considered until now. From the above-mentioned 131 cases, only 2 cases were pulmonary, being these the first reports of pulmonary dirofilariosis in Russia and the former Soviet Union. As for the rest 129 cases, the clinical presentation and the distribution of the lesions were typical of $D$. repens. It must be outlined that incidence of cases is significantly higher in women than in men. Pampigline and Rivasi [14] observed the same sex distribution of human dirofilariosis in their review of the world literature, but they 
stressed that differences were not significant. The real risk of infection of the human population living in the Rostov Region is illustrated by the fact that $10.4 \%$ of the healthy blood donors analyzed showed high levels of specific antiDirofilaria spp. antibodies. The risk seems higher among persons who professionally work with dogs, as suggested by the results obtained in policemen living in the Rostov Region, in which seroprevalence is two times higher than that observed in the random healthy population analyzed.

Prevalence of clinical cases in females (93 women out of 131 patients, or $71 \%$ ) contrasted with the gender distribution in the seropositive healthy blood donors, where 28 out of 33 seropositives $(84.8 \%)$ were male. This suggests the existence of an unknown factor in men that could be able to eliminate migrating larvae responsible of the development of the nodules.

Other interesting point is that, in spite of prevalences of $D$. repens and $D$. immitis in dogs are very similar, most of the human clinical cases are due to D. repens. Because if is difficult to differentiate among $D$. immitis and $D$. repens infections by serological tests in some cases, we can speculate if, in the studied area, there are more mosquito species adapted to transmit D. repens. Clearly, studies on the mosquito vectors present in the area are needed to elucidate the species involved in the transmission of Dirofilaria species. Moreover, we can consider the fact that subcutaneous nodules are easier to detect than pulmonary ones.

In conclusion, our data demonstrate a high infection rate of Dirofilaria spp. in canine and human population of the Rostov Region. Because in this region favourable conditions for the development of mosquito vector populations appear (a lot of water sources like rivers, lakes, basins, hot climate from April to mid-October, and wild life reservoir), it is urgent to apply measures regarding prophylaxis in dogs and control of mosquito populations to decrease the risk of infection both in dogs and humans.

\section{References}

[1] F. Simón, R. Morchón, J. González-Miguel, C. MarcosAtxutegi, and M. Siles-Lucas, "What is new about animal and human dirofilariosis?" Trends in Parasitology, vol. 25, no. 9, pp. 404-409, 2009.

[2] C. Genchi, J. Guerrero, J. W. McCall, and L. Venco, "Epidemiology and prevention of Dirofilaria infections in dogs and cats," in Dirofilaria immitis and D. repens in Dog and Cat and Human Infections, C. Genchi, L. Rinaldi, and G. Cringoli, Eds., pp. 145-161, Rolando Edirore, 2007.

[3] C. Genchi, L. Rinaldi, C. Cascone, M. Mortarino, and G. Cringoli, "Is heartworm disease really spreading in Europe?" Veterinary Parasitology, vol. 133, no. 2-3, pp. 137-148, 2005.

[4] F. Simón, J. López-Belmonte, C. Marcos-Atxutegi, R. Morchón, and J. R. Martín-Pacho, "What is happening outside North America regarding human dirofilariasis?" Veterinary Parasitology, vol. 133, no. 2-3, pp. 181-189, 2005.

[5] A. Artamonova, "Cases of dirofilariasis in the Rostov Region," in Helminthiasis in Humans, pp. 92-95, VMedA, StPetersburg, Russia, 1989.
[6] A. Artamonova, S. Nagorny, G. Strelnikova, and L. Levchenko, "Human and canine dirofilariosis in Rostov region," in Proceedings of the 7th USSR Congress of the Society of Epidemiologists, Microbiologists, Parasitologists, vol. 1, pp. 326327, Moscow, Russia, 1997.

[7] N. Levchenko, A. Ermakov, T. Derezina, and S. Nagorny, "Epizootology, diagnosis and treatment of dirofilariosis in dogs," in Proceedings of the 7th International Conference on Veterinary Medicine, pp. 148-150, Moscow, Russia, 1999.

[8] A. P. Savchenko, "Human dirofilariasis in the North Caucasus," in Problems of Parasitology, pp. 205-206, Kiev, Russia, 1972.

[9] L. H. Kramer, V. V. Kartashev, G. Grandi et al., "Human subcutaneous dirofilariasis, Russia," Emerging Infectious Diseases, vol. 13, no. 1, pp. 150-152, 2007.

[10] R. A. Acevedo, J. H. Theis, J. F. Kraus, and W. M. Longhurst, "Combination of filtration and histochemical stain for detection and differentiation of Dirofilaria immitis and Dipetalonema reconditum in the dog," American Journal of Veterinary Research, vol. 42, no. 3, pp. 537-540, 1981.

[11] G. Favia, A. Lanfrancotti, A. Della Torre, G. Cancrini, and M. Coluzzi, "Polymerase chain reaction-identification of Dirofilaria repens and Dirofilaria immitis," Parasitology, vol. 113, no. 6, pp. 567-571, 1996.

[12] F. Simón, A. Muro, M. Cordero, and J. Martin, "A seroepidemiologic survey of human dirofilariosis in Western Spain," Tropical Medicine and Parasitology, vol. 42, no. 2, pp. 106-108, 1991.

[13] M. Miterpáková, D. Antolová, Z. Hurníková, P. Dubinský, A. Pavlačka, and J. Németh, "Dirofilaria infections in working dogs in Slovakia," Journal of Helminthology, vol. 84, no. 2, pp. 173-176, 2010.

[14] S. Pampiglione and F. Rivasi, "Human dirofilariasis due to Dirofilaria (Nochtiella) repens: an update of the world literature from 1995 to 2000," in Dirofilaria immitis and D. repens in Dog and Cat and Human Infections, C. Genchi, L. Rinaldi, and G. Cringoli, Eds., pp. 81-116, Rolando Edirore, 2007. 

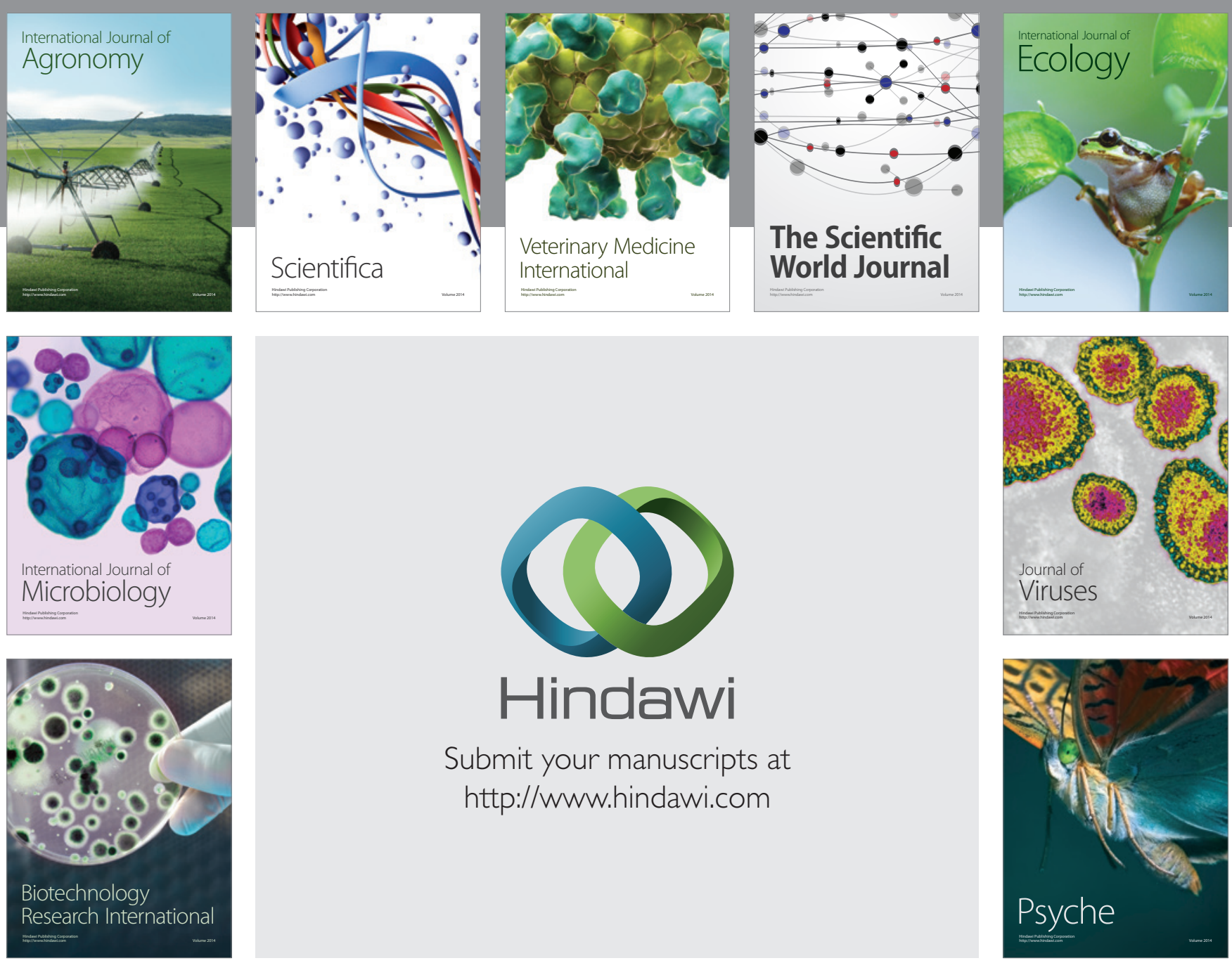

Submit your manuscripts at

http://www.hindawi.com
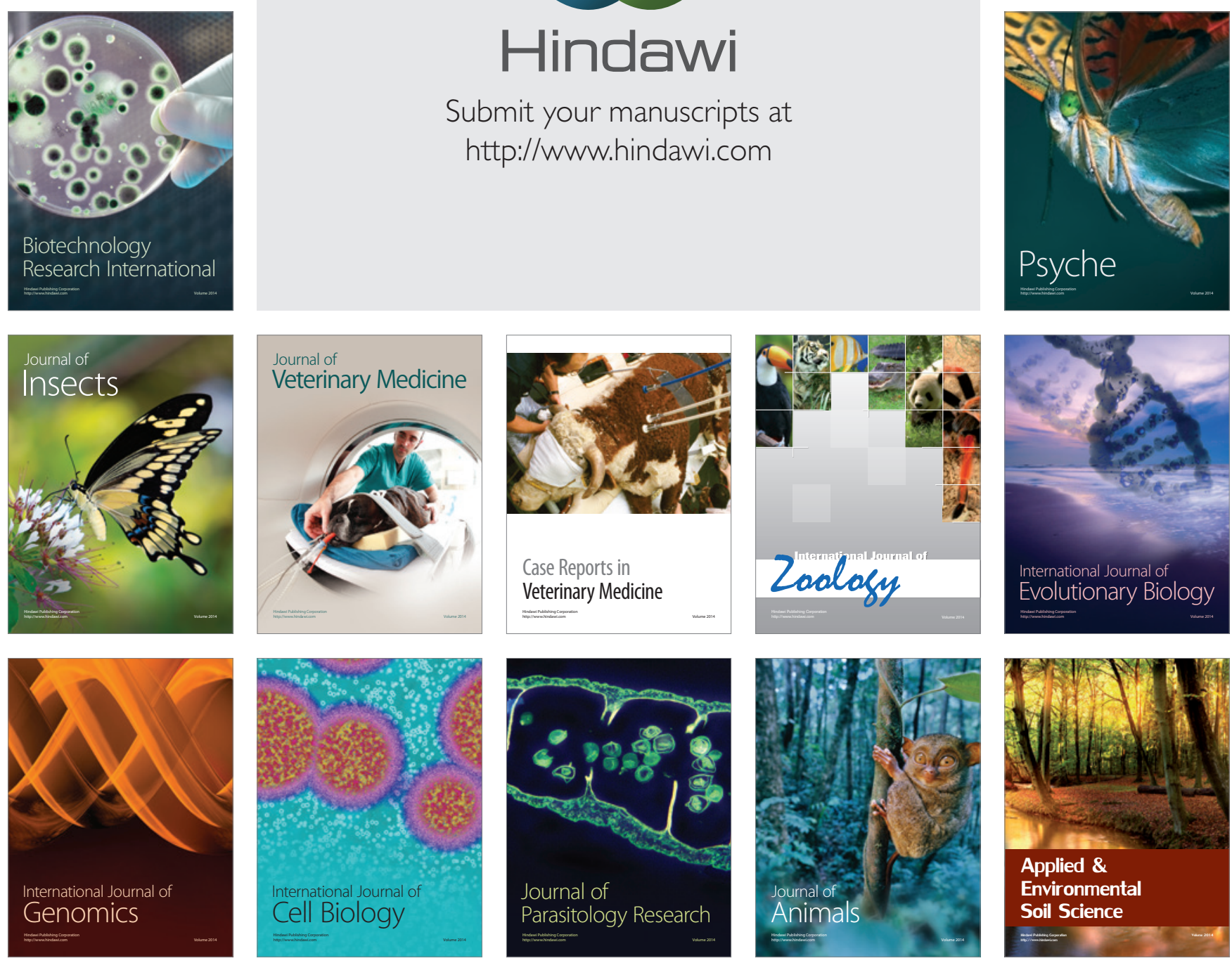